\title{
Impact of the production of wood pellets on their properties
}

\author{
Matej Palacka ${ }^{1, *}$, Michal Holubčík ${ }^{1}$, and Jozef Jandačka ${ }^{1}$ \\ ${ }^{1}$ University of Žilina, Department of Power Engineering, Univerzitná 8215/1, 01026 Žilina
}

\begin{abstract}
Process of production wood pellets is difficult and this process has an impact on the final properties of pellets. The article deals with the comparison of the energy and mechanical properties of experimental pellets that have been made under different conditions. Sample A was manufactured in laboratory conditions and sample B was made in factory production. At the end of the work are displayed the results of the experiments.
\end{abstract}

\section{Introduction}

Wood pellets are relatively used as a source of heat energy with great potential to replace fossil fuels. These pellets are made from waste material such as sawdust and shavings. Important properties of the pellets include size, shape, mechanical resistance, moisture content, volatile content, ash melting temperature and caloric value. These properties are influenced by the quality of the input material as well as by the ways and technologies of their production. The production of wood pellets is dealt with by some companies, which provide input materials from woodworking and sawmill industry. Nowadays, the cost of purchasing pelleting equipment is decreasing and for this reason more and more people and households are considering buying these instruments for producing their own domestic wood pellets.

This article discusses the energy and mechanical properties of clean sawdust pellets produced under laboratory conditions and pellets produced in a specialized plant that has been manufacturing pellets for many years.

\section{Production of samples}

Samples of wood pellets were produced in two ways:

- Sample A is from laboratory production,

- Sample B is from factory production.

Laboratory production was to simulate the production of wood pellets in domestic conditions, which is mostly used by smaller woodworking companies and carpenters, who have waste sawdust and shavings. A pellet press (Figure 1) with a theoretical production of $200 \mathrm{~kg}$ pellets per hour was used to produce the experimental samples, but under realistic

*Corresponding author: matej.palacka@,fstroj.uniza.sk 
conditions, only about $80-100 \mathrm{~kg}$ pellets per hour were obtained during experimental production. The sample A (Figure 1) was made from pure sawdust on this machine. Factory production of wood pellets was carried out at a specialized facility in an external laboratory (Figure 2, illustrative photo). The production line used has a production capacity of approximately $1000 \mathrm{~kg}$ pellets per hour. Sample B (Figure 2) was formed on this machine from the same input material as for sample A. The input material came from spruce sawdust from a private sawmill located in northern Slovakia. The preparation of the base material consisted in adjusting the moisture to the required parameters. As the material delivered reached a moisture content of $8.11 \%$, in the case of a small laboratory production of wood pellets, the sawdust needed to be dampened to about $15-17 \%$. In the case of the production of wood pellets on the production line, the humidity was controlled by the operator to approximately $12-15 \%$ depending on the output quality of the wood pellets.
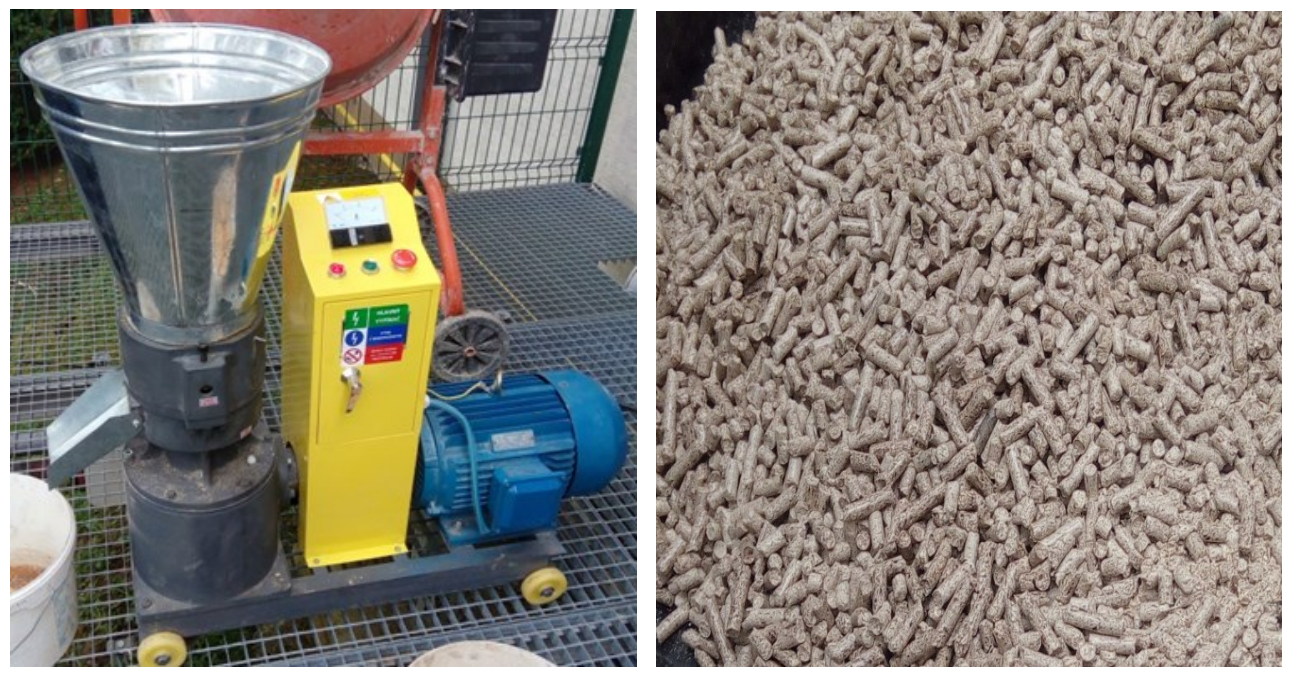

Fig. 1. Laboratory device and sample A.
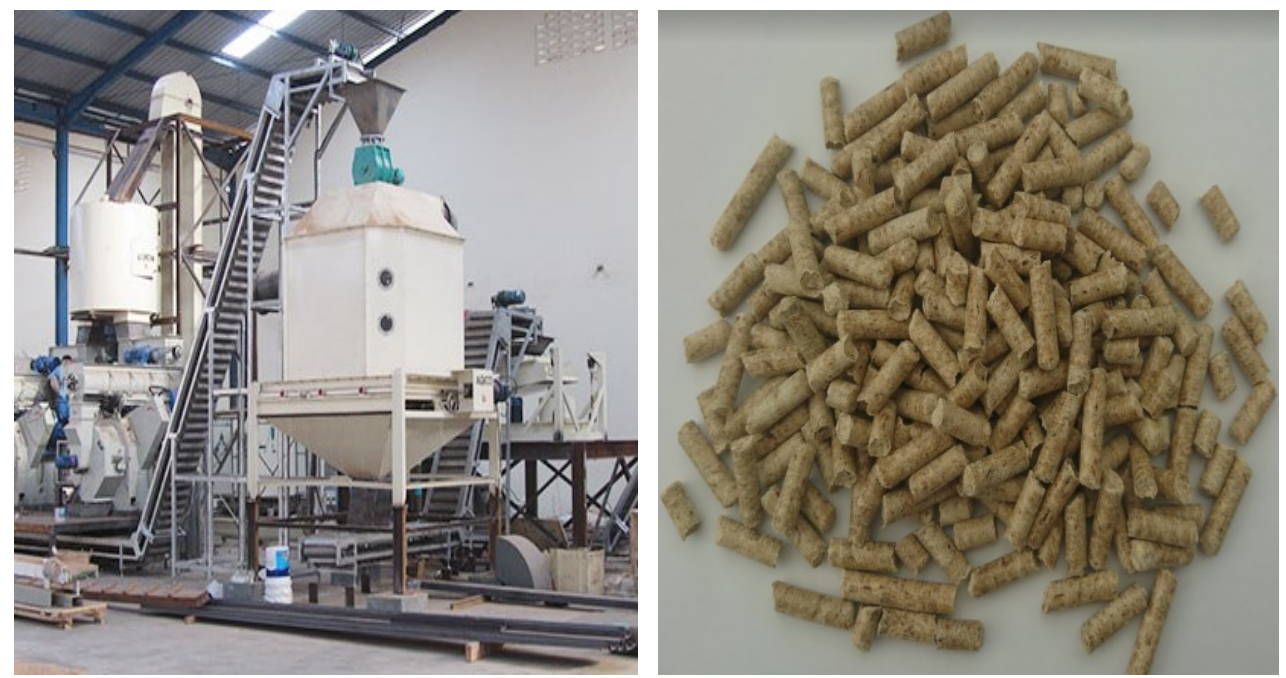

Fig. 2. Specialized device and sample B. 


\section{Experiments}

During the experiments were determined moisture, volatiles, fixed carbon content, ash content, elemental analysis, gross calorific value and calorific value obtained using these devices:

- First thermogravimetric analyzer (TGA, Figure 3) - is used to determine the composition of the organic, inorganic or synthetic materials. Measured by weight loss as a function of temperature in a controlled environment in a predefined atmosphere. The device consists of a computer and a muffle furnace that allows monitoring of up to 19 samples to be analyzed simultaneously. Empty cups on the samples are placed in carousel the furnace after selecting the method of analysis. The analysis method controls the carousel, furnace, and operating weights that gradually weigh all samples were placed on the carousel. After weighing all the crucibles, is each a crucible is gradually adjusted for the operator of device for the sample application. Individual weights of samples are measured and saved automatically. When all the crucibles are loaded begins analysis. The loss in weight of each sample was monitored and the temperature of the oven is controlled according to the chosen analytical method. The percentage weight loss of each sample is known at the end of every step of the analysis. The device is easy to use with a software program Windows that allows analytical methods that can be designed to meet the most analytic applications according to current norms. The temperature, speed of rising temperatures and atmosphere are optional for each step. Thermogravimetric analyzer can determine the moisture, volatiles, fixed carbon and ash but also combination of all these parameters. In this work thermogravimetric analyzer measured the moisture, the proportion of solid carbon and volatile matter and ash content.
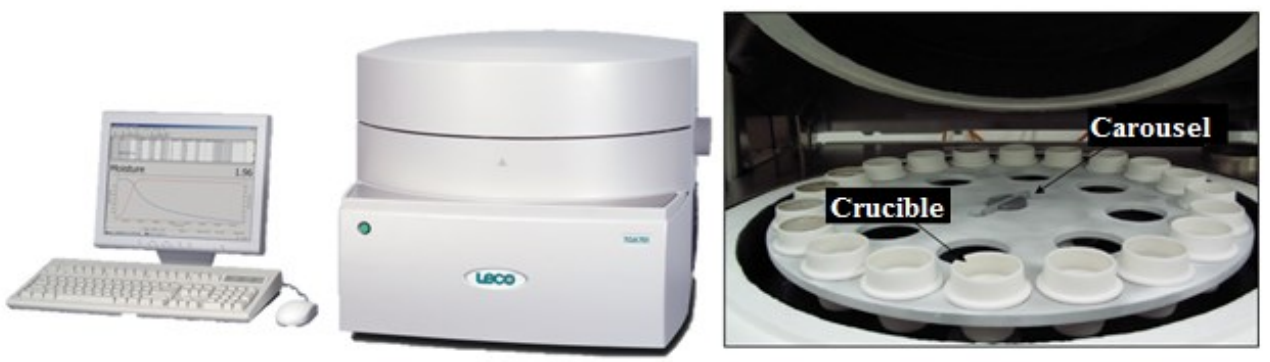

Fig. 3. Termogravimetric analyser.

- Elemental analyzer (Figure 4) - is a device for elemental analysis of organic samples. The device in the combustion chamber burns weighed sample in the absence of atmospheric gases and after burning comes detecting the resulting gases. The device has a separate module for the determination of sulfur. Sample is also combusted, but at a higher temperature $\left(1350^{\circ} \mathrm{C}\right)$ to detect the presence of sulfur oxides.
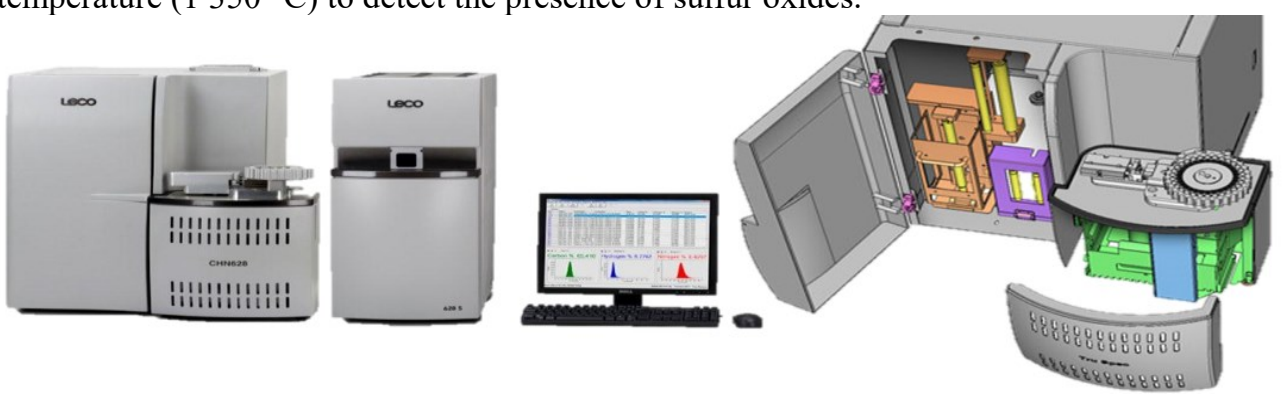

Fig. 4. Elemental analyser. 
- Calorimeter (Figure 5) - calorific value of biofuel samples was determined according to STN EN 14918 through the calorimeter LECO AC 500. From the measured gross calorific value, measured relative moisture and the contribution of hydrogen is determined calorific value spruce wood from the following equation:

$$
Q_{\mathrm{i}}=Q_{\mathrm{s}}-2.453\left(M_{\mathrm{ar}},+9 H\right)
$$
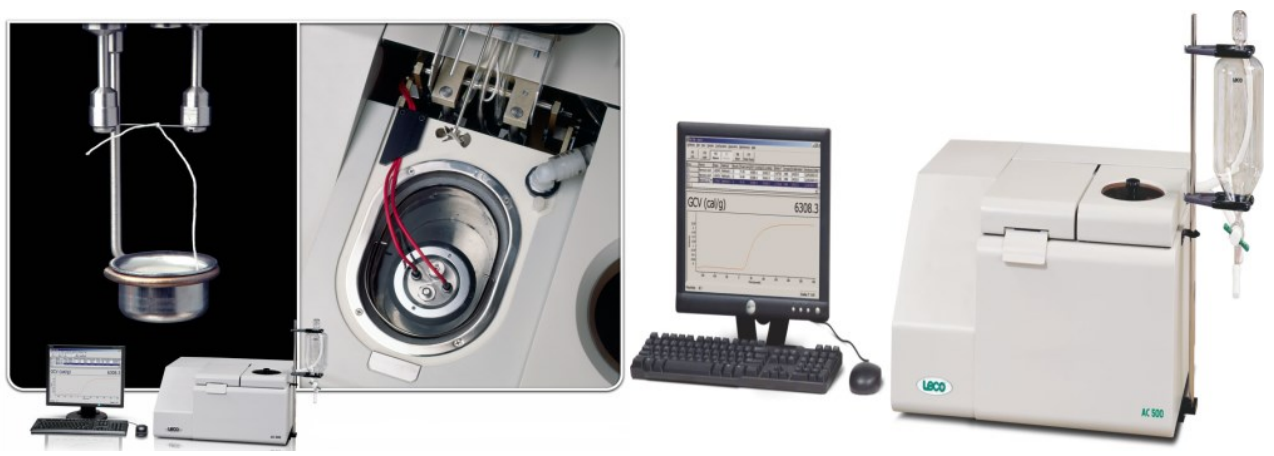

Fig. 5. Calorimeter.

\section{Experiment results}

The results of the experiments are shown in the table (Table 1). Moisture content, volatile matter, solid carbon and ash in wet and dry conditions.

Table 1. Results of experiments.

\begin{tabular}{|c|c|c|c|}
\hline & & Sample A & Sample B \\
\hline Moisture & {$[\%]$} & 7.33 & 6.50 \\
\hline Volatile & {$[\%]$} & 81.66 & 81.91 \\
\hline Fixed carbon & {$[\%]$} & 17.89 & 17.58 \\
\hline Ash & {$[\%]$} & 0.48 & 0.51 \\
\hline Volatile (dry) & {$[\%]$} & 75.56 & 76.45 \\
\hline $\begin{array}{c}\text { Fixed } \\
\text { carbon(dry) }\end{array}$ & {$[\%]$} & 16.55 & 16.41 \\
\hline $\begin{array}{c}\text { Ash(dry) } \\
{[\%]}\end{array}$ & 0.45 & 0.48 \\
\hline
\end{tabular}

The table (Table 2) shows the results of the fine particle fraction and the abrasion resistance of samples $\mathrm{A}$ and $\mathrm{B}$, these values influencing the mechanical properties of the pellets. 
Table 2. Results of experiments.

\begin{tabular}{|c|c|c|c|c|c|c|}
\hline & \multicolumn{2}{|c|}{ F test (g) } & \multirow{2}{*}{$\begin{array}{c}\text { The } \\
\text { proportion } \\
\text { of fine } \\
\text { particles } \\
\text { (g) }\end{array}$} & \multicolumn{2}{|c|}{ DU test (g) } & \multirow{2}{*}{$\begin{array}{c}\text { The } \\
\text { abrasion } \\
\text { resistance } \\
(\%)\end{array}$} \\
\hline & Before & After & & Before & After & \\
\hline Sample A & 100.23 & 98.90 & 1.33 & 100.20 & 96.65 & 96.46 \\
\hline Sample B & 107.892 & 107.865 & 0.027 & 107.865 & 107.335 & 99.509 \\
\hline
\end{tabular}

The table (Table 3) shows the results of moisture, gross calorific value, calorific value of samples A and B.

Table 3. Results of experiments.

\begin{tabular}{|c|c|c|c|c|c|}
\hline & $\begin{array}{c}\text { Moisture } \\
(\%)\end{array}$ & \multicolumn{2}{|c|}{$\begin{array}{c}\text { Gross calorific value } \\
\text { (MJ/kg) }\end{array}$} & $\begin{array}{c}\text { Gross calorific } \\
\text { value (MJ/kg) }\end{array}$ & $\begin{array}{c}\text { Calorific value } \\
\text { (MJ/kg) }\end{array}$ \\
\hline Sample A & 7.33 & 18.8363 & 18.7560 & 18.7962 & 17.3121 \\
\hline Sample B & 6.50 & 19.9657 & 19.7683 & 19.8670 & 18.3626 \\
\hline
\end{tabular}

Different moisture values have been caused by a different production method, in particular the need for greater moisture demand in the case of domestic (laboratory) production of wood pellets. Volatile and solid carbon values are roughly identical due to the same input material - spruce sawdust. Ash content for samples A and B are almost identical. Experiments to determine the fine particle size and abrasion resistance proved that under domestic conditions, on a conventional small pelletizing press, it is not possible to produce sufficiently solid wood pellets in view of the fact that high pressing pressures and pressures can't be achieved as in the case of the large pelletizing press in the production line. Sample A achieved lower calorific value and gross calorific value than sample B, due to higher moisture content in sample A by other production methods. Therefore, it results from the measured values that sample A was of lower production quality than sample B. In the case of combustion in a conventional heat source for pellet burning, this causes wood pellets produced in the small pelletizer to be decomposed more rapidly during the feeding and during the combustion and thus can't achieve the same heat output and efficiency of the heat source as the wood pellets produced in a large production line. During the operation of the heat source, this would result in higher pellet consumption and higher emissions.

\section{Conclusion}

The difference between commercial and domestic wood pellet production is quite clear from the results obtained. In domestic conditions on small pelletizing presses, high pressing pressures and temperatures can't be achieved, as in the case of the production of wood pellets on a production line with high production. The produced wood pellets differ mainly in qualitative mechanical parameters, when domestic wood pellets are rather decaying, thereby reducing the bulk density, which is negative in their combustion. However, unless the commercial use of wood pellets is anticipated and their domestic consumption is assumed, it is important to produce wood pellets in small pellet presses. 
This work was supported by the projects APVV-15-0790 "Optimization of biomass combustion with low ash melting temperature" and 046ŽU-4/2016 "Unconventional systems using renewable energy “.

\section{References}

1. L. Dzurenda, A. Banski, Archives of Thermodynamics, 38, 1 (2017)

2. L. Dzurenda, L. Pňakovič, Annals of Warsaw University of Life Sciences, (2014)

3. J. Beniak, P. Križan, L'. Sooš, M. Matúš, Waste Forum, 5 (2017)

4. L. Soos, M. Kolejak, F. Urban, Vert: Bratislava, (2012)

5. L. Martiník, V. Drastichová, J. Horák, Z. Jankovská, K. Krpec, P. Kubesa, F. Hopan, Z. Kaličáková, Chemicke Listy, 108, 2 (2014)

6. M. Carnogurska, M. Prihoda, M. Koško, R. Pyszko, J. of Mech. S. and Tech., (2012)

7. J. Geffertova, A. Geffert, Acta Facultatis Xylologiae, 53/1 (2011)

8. J. Chabadová, Š. Papučík, R. Nosek, AIP Proceedings, 1608, (2014)

9. A. Čaja, P. Nemec, M. Malcho, AIP Proceedings, 1608, (2014)

10. P. Taus, M. Tausova, Acta Montanistica Slovaca, 14, 1 (2009)

11. P. Nemec, M. Smitka, M. Malcho, Scientific world journal, 2014 (2014) 